This article was downloaded by: [University of Southampton]

On: 28 July 2009

Access details: Access Details: [subscription number 773565842]

Publisher Routledge

Informa Ltd Registered in England and Wales Registered Number: 1072954 Registered office: Mortimer House, 37-41 Mortimer Street, London W1T 3JH, UK

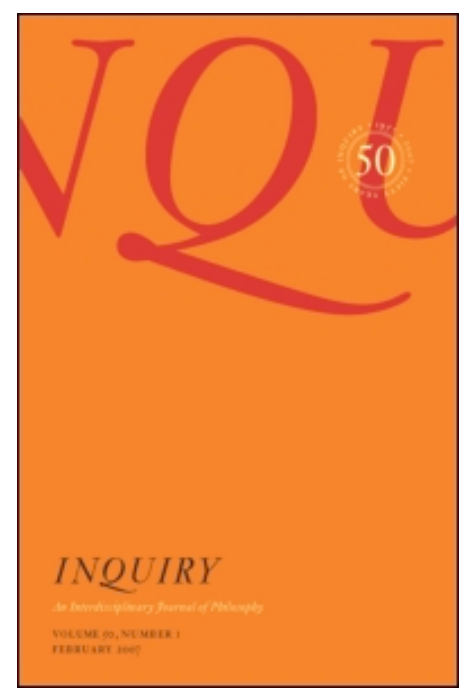

\title{
Inquiry
}

Publication details, including instructions for authors and subscription information:

http://www.informaworld.com/smpp/title content=t713393858

\section{Acting Intentionally and Acting for a Reason}

\section{Maria Alvarez a}

a University of Southampton, UK

Online Publication Date: 01 June 2009

To cite this Article Alvarez, Maria(2009)'Acting Intentionally and Acting for a Reason', Inquiry,52:3,293 - 305

To link to this Article: DOI: $10.1080 / 00201740902917168$

URL: http://dx.doi.org/10.1080/00201740902917168

\section{PLEASE SCROLL DOWN FOR ARTICLE}

Full terms and conditions of use: http://www.informaworld.com/terms-and-conditions-of-access.pdf

This article may be used for research, teaching and private study purposes. Any substantial or systematic reproduction, re-distribution, re-selling, loan or sub-licensing, systematic supply or distribution in any form to anyone is expressly forbidden.

The publisher does not give any warranty express or implied or make any representation that the contents will be complete or accurate or up to date. The accuracy of any instructions, formulae and drug doses should be independently verified with primary sources. The publisher shall not be liable for any loss, actions, claims, proceedings, demand or costs or damages whatsoever or howsoever caused arising directly or indirectly in connection with or arising out of the use of this material. 


\title{
Acting Intentionally and Acting for a Reason
}

\author{
MARIA ALVAREZ \\ University of Southampton, $U K$
}

(Received 17 December 2008)

\begin{abstract}
This paper explores the question whether whatever is done intentionally is done for a reason. Apart from helping us to think about those concepts, the question is interesting because it affords an opportunity to identify a number of misconceptions about reasons. In the paper I argue that there are things that are done intentionally but not done for a reason. I examine two different kinds of example: things done "because one wants to" and "purely expressive actions".

Concerning the first, I argue that the tendency to think that things done because one wants to are things done for a reason derives from conflating the reason that explains why someone did something with their reason for doing it. While these sometimes coincide, they need not always do so. And although the fact that someone wanted to do something can contribute to explaining the person's action, it is not normally that person's reason for doing that thing.

Purely expressive actions also provide examples of things done intentionally but not for a reason. I argue that, although those actions are spontaneous, they are nonetheless intentional and that, since they are mere expressions of emotions, they are not done for reasons - although there are reasons why we do them.
\end{abstract}

\section{Introduction}

The question I am going to explore in this paper is whether whatever is done intentionally is done for a reason. I take it that the converse is true: everything that is done for a reason is done intentionally. But it seems possible that there are things that are done intentionally but not for a reason.

I think the question is interesting because it makes us think about the concepts of doing something intentionally and doing something for a reason,

Correspondence Address: Maria Alvarez, Department of Philosophy, School of Humanities, University of Southampton, Highfield, Southampton, SO17 1BJ, UK. Email: m.alvarez@, soton.ac.uk 
respectively, and also about the relation between them. Moreover, it affords an opportunity to re-examine certain kinds of example generally regarded in the literature as cases of things done for reasons but which I think are not. And this is important because the view that those things are done for reasons has contributed to a number of misconceptions about reasons - but I won't be able to go into that here.

Exploring the question whether there are things that are done intentionally but not done for a reason requires at least a working characterisation of both doing something intentionally and doing something for a reason. I'll attempt to characterise them in that order.

\section{Doing something intentionally}

It is difficult to give a characterisation of what doing something intentionally is without falling into mere stipulation. I will do my best to avoid the latter.

First, doing something intentionally is often contrasted with doing it accidentally, or by mistake, or in ignorance, and it is associated with meaning to do it, doing it consciously, etc. I think these give us a clue to two features that seem to be required for doing something intentionally: some awareness of what one is doing, and some degree of control over it.

These concepts introduce their own complications. For instance, does doing something intentionally require that one knows that one is doing that thing? In Intention, Anscombe introduces the idea of "practical knowledge" as a special kind of knowledge we have of what we do intentionally (Anscombe, 1957, p. 50ff.). By constrast, Davidson famously argued that knowledge is not necessary for intentional actions, and used the example of making copies with carbon paper to support his claim. He wrote:

a man may be making ten carbon copies as he writes, and this may be intentional; yet he may not know that he is; all he knows is that he is trying (Davidson, 1980, p. 50).

Davidson is surely right that a man may be trying to make ten carbon copies without knowing whether he is succeeding, perhaps even doubting that he is. And, if he does succeed, since making ten carbon copies is what he was trying to do, it would seem that he made the ten copies intentionally. If this is right, then it seems that the knowledge condition needs to be modified; perhaps it should be construed as a disjunction: if A does something, X, intentionally, then A knows either that he is doing $\mathrm{X}$, or that he's doing something else, Y, with the intention of doing X. But it still seems that some kind of awareness of what one is up to is required.

The other feature mentioned above is control. Exactly what degree of control is required for doing something intentionally has also proved to be a signally controversial issue. Some have argued that the control required involves the 
ability to refrain from doing what you did. Others deny this. For instance, much discussion generated by Harry Frankfurt's arguments against the principle that a person is morally responsible for something he does only if he could have "done otherwise" focuses precisely on this issue (Frankfurt, 1969). Frankfurt's arguments were intended to show that a man may do something, e.g. shoot another man, "for reasons of his own", even though he could not have acted otherwise (i.e., could not have failed to shoot the other man). So if Frankfurt's arguments are right, one could do something for a reason even though one could not have acted otherwise; and a fortiori, one could do something intentionally even though one could not have acted otherwise. And this would mean that the control required for doing something intentionally is not the control to do it or to refrain from doing it.

Frankfurt's arguments generated a great deal of controversy, as many have been reluctant to abandon the view that moral responsibility requires the ability to act otherwise. For myself, I am inclined to think that doing something intentionally requires the capacity to act otherwise, and have argued against Frankfurt's arguments elsewhere (see Alvarez, 2009). But perhaps we do not need to choose between these two positions here, as both agree that some degree of control is required.

So we may say that doing something intentionally requires some awareness of what one is doing and some control over it - however those are to be cashed out. If one does something without knowing that one is doing it or that one is trying, or without any control over it, then one does not do that thing intentionally.

These seem minimal conditions for doing something intentionally. A further question is whether more is required and if so, what that might be.

One obvious suggestion comes to mind here, namely that doing something intentionally requires intending to do that thing. ${ }^{1}$ But, what is added to our characterisation of doing something intentionally by saying that, if someone does something intentionally, then she intended to do that thing? I think not much need be added by saying this. This is because, although intending to do something may involve having a prior and explicit intention to do it something like a conscious mental episode in which the intention is formed - it need not. For the claim "A intended to open the door" may be construed to involve simply the following: as A was engaged in whatever activity she was engaged in - say, turning the handle - opening the door was the outcome towards which that activity was directed by her. So this would be a case where A intended to open the door and where, if she succeeded, she opened the door intentionally, but where there needn't have been any conscious mental episode that consisted in A's forming the intention to open the door.

Given this characterisation of what doing something intentionally is, we can put aside certain examples of things that we do which fall short of being done intentionally. Here are some examples: changes in posture and position of one's limbs done without being aware that one is doing those things; for 
instance, crossing and uncrossing one's legs, resting one's head on one's hand, leaning on one's elbow, etc.; or fidgeting and similar, doings such as twiddling with one's hair, rocking one's foot, rubbing one's chin, rapping one's fingers on the table, etc., when these are done without awareness. (There may be other kinds of example).

By "done without awareness" here, I do not mean instances where one knows that one is doing something although one is not attending to it, or not especially attending to it, at the time when one is doing it. Rather I mean that one is not at all aware, as one is doing that thing, of doing it - even if one knows, in general, that one tends to do that kind of thing. So I may know that I tend to move my hands in a certain way when speaking and do it while, say, asking a question at a seminar, without being aware then that I am moving my hands so.

This kind of phenomenon has been discussed by philosophers. Aquinas, for example, says that actions such as moving one's foot or scratching one's beard "when intent on something else" are not actions that belong to humans qua humans because they do not require the capacity to reason -i.e., they do not require the capacity for abstract thought (see $S T$, 1a2ae, q1, a.1). Brian O'Shaughnessy has discussed this phenomenon in detail. He argues that, sometimes, I may do something, such as move my tongue or my toes, and that such an act is an action of mine, even though I have no awareness that I am doing that thing "under any and all descriptions of it" (O'Shaughnessy, 1980, vol. 2, p. 58). According to O'Shaughnessy, these are not things I do intentionally, since I have no awareness of doing them, but they are my actions because they are not, he says, things that happen to me; rather, according to him, these are "movements that I have executed", and for which "I, my mind, and brain are responsible" (Ibid.). O'Shaughnessy calls these actions "subintentional actions".

Whether acts of this kind are rightly characterised as O'Shaughnessy suggests or not, I think it is clear that they are not things we do intentionally, since there isn't the required awareness. So, in a sense, I mention them to note their existence and then put them aside. I shall now turn to the characterisation of doing something for a reason.

\section{Doing something for a reason}

I shall suggest that someone does something for a reason if she does it in the light of some fact that she is aware of, and in pursuit of a goal. A fact in the light of which someone acts I take to be the reason for which she acted; ${ }^{2}$ and that in pursuit of which an agent acts, I take to be the agent's goal in acting.

In the more common formulation of what acting for a reason is, reasons are characterised as combinations of an agent's beliefs and desires, and agents are said to act in the light of their beliefs and in fulfilment of their desires. I have not articulated my characterisation using those terms for a 
variety of reasons, among which is that that formulation encourages the view that an agent's reason for acting is a mental state (or a combination of mental states) of his, which I think is mistaken. ${ }^{3}$

A fact in the light of which an agent acts is something that, in the agent's eyes, makes his doing the thing in question good or valuable, either instrumentally or non-instrumentally, and in relation to a variety of criteria: for example, ethical, aesthetic, hedonic, prudential, and so on.

Since things can seem good either instrumentally or non-instrumentally, our reasons may also be instrumental or non-instrumental. When something is done for an instrumental reason, the reason for doing it is that it is a means of achieving some further good (or further apparent good). Sometimes the action seems to be the best means, sometimes the only means, and sometimes just a convenient or satisfactory means. For example, the fact that a shop sells milk is normally an instrumental reason for me to go to the shop, because the good of my going to the shop is instrumental: it will enable me to buy milk. Going to the shop is a means to achieve my end: obtaining milk. There may be other means of doing this: finding a cow and milking it, stealing some milk from my neighbours' doorstep, etc. But, I may not consider those other options and simply decide to go an buy some milk in the shop, since they sell milk there.

By contrast, when a fact is someone's intrinsic reason for doing something, that fact makes doing the thing good or valuable in itself, or at least seems to the agent to do so. For example, that doing something is enjoyable, healthy, an act of friendship, and so on, are facts that could, in someone's eyes, make doing that thing intrinsically good. When I do something for its own sake I still do it for a reason, namely that doing it is (or seems to me to be) good-whether it is morally good, prudentially good, hedonically good, legally good, or good in some other way.

When something is done for an instrumental reason, it is always possible to ask "Why?" again, until the answer is a non-instrumental reason: that is, something that, to the agent, makes his doing that thing good or valuable in itself. Because of this, we may say, paraphrasing Anscombe, that when something is done for its own sake, the agent's answer to why he did that thing will "make an end of the question 'Why?" (Intention, p. 74. She makes this point in relation to asking why one wants something).

This characterisation of doing something for a reason leaves open the question what it is for someone to act for a reason - or to use my characterisation, what it is for someone to act in light of. This is something that philosophers have tried to elucidate in a variety of ways. The most familiar way is one that claims that the elucidation must invoke ineliminably the notion of causation in characterising the relation between the agent's reason (or, more plausibly, the agent's believing and wanting something) and his action. I shall not say anything about this issue here but will simply assume the concept of "acting in light of a fact". 
With these characterisations in place, we can now turn to the question whether there are things that are done intentionally but not for a reason.

\section{Doing something for no reason}

Suppose that I am walking down an empty corridor and conceive the idea of doing a cartwheel, and with it the desire to do it. I don't do the cartwheel to exercise, or to see whether I am still capable of doing a cartwheel. I simply do it because I feel like doing it. Similar examples are: pulling a face at someone in the middle of a meeting (but not, say, in order to make them laugh), skipping as one walks along the road, touching a spot on the wall, etc.

These examples seem to fulfil the criteria set out above for doing something intentionally. For instance, as I do the cartwheel - I'm assuming that I know that I can still do cartwheels - I know that I am doing a cartwheel, and doing it is within my control. This may not always be the case: perhaps it is possible to do a cartwheel without realising one is doing it - that seems a little implausible in general but perhaps not for someone who is in the habit of doing cartwheels. And perhaps it is possible to feel an irresistible compulsion to do a cartwheel, in which case one may wonder about the degree of control. But it is surely plausible to say that I may do a cartwheel knowingly and while being in control of what I do - we could imagine that I do it with some premeditation: once the idea has come to my mind, perhaps I first look around to make sure there indeed isn't anyone looking, and then do the cartwheel. And this is the kind of case I want to examine.

Now, doing a cartwheel in such circumstances seems to me an instance of doing something intentionally but not for a reason. This instance of cartwheeling is quite different from an instance when one does it while training, or for an exam, or as part of a routine in the Olympics, or because one enjoys doing cartwheels. In those cases, it is relatively easy to come up with reasons for which one does cartwheels. In my example, by contrast, it seems perfectly plausible to say that I did it for no reason: there was no end or purpose in pursuit of which I did it, nor any fact that, in my eyes, made doing it seem good or valuable. There is, as we may say, nothing to be said for doing it, I just felt like doing it - except perhaps that there was nothing to be said against doing it. So I did it for no reason and yet I did it intentionally.

Surely, one may object, to say that I did the cartwheel for no reason in this kind of case is just a way of saying that I did it simply because I wanted to, that is, it is a way of saying that I did it for no other reason than that I wanted to do it. So I did do it for a reason, the objector says, namely that I wanted to do it. And if that is right, then I did the cartwheel intentionally but also for a reason.

I find this response unpersuasive. When I do something for a reason, there must be some aspect of the action that seems to me good or valuable in some sense, some "desirability characterisation" (to use Anscombe's phrase; see 
Intention, pp. 77-8) that the action has for me. In the example there is nothing, ex hypothesi, that makes the action appear to me as good or worthwhile, and my wanting to do it does not supply this: the good I see in what I want is not that I want it, for things do not seem desirable to me because I desire them but rather I desire them because they seem desirable to me - even when it might be quite difficult to articulate precisely what makes them so. To borrow an example from Anscombe, what makes my acquiring a pin desirable to me cannot simply be that I desire to acquire one: there must be something about acquiring a pin that makes it seem good because, e.g., it's fun, reassuring, etc. - which is my reason for wanting to acquire it and for acquiring it. But if I insist in saying that there's nothing to be said for it and that I acquired it simply because I wanted to, then it seems to follow that I acquired the pin for no reason.

An argument given to support the opposite claim, namely that when you do something simply because you want to, your wanting to do that thing is your reason for doing it, is that, in examples of this kind, your wanting to do the thing plays a central role in the explanation of your doing that thing, a role that fits the pattern of Davidson's model for reason explanations of action. ${ }^{4}$ But I think this arguments fails. First, it is not clear that this example fits the Davidsonian model. According to Davidson,

C1. $R$ is a primary reason why an agent performed the action A under the description $d$ only if $R$ consists of a pro attitude of the agent towards actions with a certain property, and a belief of the agent that $A$, under the description d, has that property (Davidson, 1980, p. 5).

If we apply this model to our example, we get: "I did a cartwheel because I had a pro-attitude (e.g. a desire) towards actions with a certain property (namely, the property 'being a cartwheel'), and also had a belief that my action $\mathrm{A}$, under description $d$ (namely 'doing a cartwheel'), had that property"; or more conversationally, "I did a cartwheel because I wanted to do a cartwheel and believed that my action of doing a cartwheel was what? a means? an instance? a way? of doing a cartwheel". But this barely makes sense, and the only reason to claim that I had such a belief is that then the example will fit the Davidsonian model. ${ }^{5}$

Second, it seems to me true that we can cite my wanting to do a cartwheel, or my feeling like doing it, to explain my action. But this does not show that my wanting to do it was $m y$ reason for doing the cartwheel. For the fact that a reason explains why someone did something does not show that that was the agent's reason for doing that thing, since not all explanations of why someone did something give the agent's reason for acting. The reason why Fred sits at the back of the class may be that he is shy but the fact that he is shy is not his reason for sitting there (his reason may be that the teacher is less likely to see him if he sits there). 
I must emphasize that I am not claiming that people never do things just because they want to, or because they feel like doing them. What I am trying to say is that, when they do, and there is no more to say about their reasons for wanting to do them, their action will be an action not done for a reason, even though it may have been intentional and even though we can explain why the agent did that thing by saying that they wanted to do it, or felt like doing it.

It should be noted that doing something because you want to, or feel like doing it, is different from doing something because you like or enjoy doing that thing, or because doing that thing will be fun. If the reason why you did something is that you like or enjoy doing that thing, then your reason for doing that thing is, normally, that you like or enjoy it, which is perfectly intelligible as your reason for acting - though, as Anscombe says (Intention, pp. 72-77), there are limits here. The limits are not those of morality or propriety but of intelligibility, for sometimes it is difficult to see what the pleasure of doing a particular thing might be - for instance, the pleasure of sitting in the Economy section of a budget airline plane for ten hours. And it is true that if one feels like doing something, this may well be because one imagines that doing that thing will, in some way, be pleasant or agreeable. If so, then perhaps the reason for doing it is that it will also be pleasant and not merely that you feel like doing it. But that would be different from the case where one simply does it because one wants to, or feels like it, while not having anything to say about what the good of doing that thing is, and where doing that thing seems to serve no purpose.

Perhaps resistance to the thought that there are things we do intentionally but not for a reason is rooted in the thought that things that are not done for a reason are irrational. However, the examples I have given do not seem examples of particularly irrational actions: at any rate, we can understand why people do them perfectly well.

Irrationality can, however, be understood in (at least) two ways. One involves doing something that goes against reason. In that sense these actions are not irrational. In another sense, irrationality is to be understood as involving acting in a way that is not dictated by reason. In that sense, doing this kind of thing is irrational - or better non-rational, or a-rational. This kind of behaviour is sometimes described as doing something crazy, or just "for the hell of it", etc. But irrationality, or craziness, is also, in a sense, a matter of degree. I mean that if someone does this kind of thing now and again, we're unlikely to think much of it. We'll think that they are pretty normal - indeed, perhaps it's not normal not to do things like this now and again. But when someone's behaviour frequently or largely falls into this kind of pattern, then the grounds for describing their behaviour, and perhaps them, as crazy or irrational become stronger. ${ }^{6}$

To sum up. There are things we do simply because we want to or feel like doing them, where we are aware and in control of what we are doing, but 
where there is no reason for which we do them: there is no goal for the sake of which that thing is done, nor is there any intrinsic worth or value that we see in doing them: we simply do such things. So these seem to be things done intentionally but not for a reason.

\section{Actions and expressions of emotions}

I shall move on to a different kind of case that also seems to provide examples where one does something intentionally but not for a reason. Raz discusses examples of this kind, which he calls "purely expressive actions", in his illuminating paper "Agency, Reason and the Good" (in Raz, 1999). His discussion relates to a challenge (posed by, e.g., Rosalind Hursthouse, in Hursthouse, 1991) to what he terms "the Classical approach" to the explanation of actions. According to Raz, the Classical approach "takes acting for a reason to be the distinctive and central case of human agency", and it explains reason "in part by invoking value" (Raz, 1999, p. 22). Moreover, he says, according to the Classical approach, "intentional action is action for a reason", and "reasons are facts in virtue of which those actions are good in some respect and to some degree" (1999, p. 23).

So what are these purely expressive actions? Consider an example of someone shouting out of anger. A person may shout because he is angry and do so intentionally and for a reason. Thus, I may shout in order to make some point, for instance, to show how important the object of my anger is and because, in the circumstances, shouting is the way to bring the point home. Or I may shout in order to relieve my anger, perhaps because it is a way of releasing tension and thus of reducing my stress levels. In such cases I shout for a reason, and my reason for shouting is that (as I think) this is the only way to drive my point home, or that it's the way to release the tension and stress caused by my anger. But a person may shout because he is angry and yet not do so for any reason or in pursuit of any goal. And often, when a person shouts because he is angry, this is how it is: he does not shout for a reason, and his shouting is simply an expression of his anger: that person, we might say, shouts in anger. If so, this would be a purely expressive action.

The same seems true of actions that are merely expressions of joy or cheerfulness, and of certain things done out of fear, etc. Consider someone who dances on hearing some good news: dancing maybe an expression of her joy without it being true that she dances for a reason, or with any purpose, although the fact that she feels joyful explains her dancing.

Raz acknowledges that these examples seem to be a challenge to the Classical approach because they seem to be things that are done intentionally but not for a reason. However, he thinks this is not quite right. And, in his discussion of these examples, Raz says two things (though he says them in a tentative way) that are intended to undermine the conviction that these are things done intentionally but not for a reason. The first thing he says, which is 
intended to suggest that these are less than fully intentional actions, is that actions of this kind, unlike paradigmatic intentional actions, "involve a small loss of control" (1999, p. 41) and in particular are likely to involve a diminution of control "over the initiation of the action" because "they explode from within without [an] element of calculation" (1999, p. 42). The second thing he says, which is offered against the idea that these are things not done for a reason, is the consideration that these are "actions with a story from the point of view of the agent, a story which can serve as a reason - it merely did not function as a reason" $(1999$, p. 43).

Concerning the first, I am simply not persuaded that examples of this kind typically involve a diminution of control. In fact, it seems to me that Raz describes the kind of control typical of these cases accurately when he says that, in these actions, "we merely allow the emotion to express itself, the will acting as a non-interfering gate-keeper" (Ibid., p. 44). But the fact that the will does not interfere and merely allows the emotion to be expressed in this way does not mean that we, our wills, are not wholly in control. This would follow only if the will were unable to interfere - but we have no reason to conclude that that need be so. As Raz points out in the examples that concern us, agents typically "do not disapprove of their actions" (1999, p. 43), at least at the time of doing them. And that, rather than inability to control, explains why agents do not suppress or exercise more control over their actions. Thus, suppose I feel a surge of enthusiasm on hearing some news and grab the person standing next to me and dance with her. I allow my enthusiasm to manifest itself: since I do not see any reason not to do it, my will doesn't intervene to curb my enthusiasm. And it doesn't seem true that this behaviour need involve some diminution of control on my part. So, I don't think that the claim that these actions involve less control than normal actions can be justified by the consideration that the agent did not exercise more control - e.g., did not suppress or mitigate her behaviour.

Perhaps this is easier to accept when the emotion manifested is a positive emotion (joy, affection, love) as one is less likely to have a reason not to manifest that emotion, or not to manifest it in such an exuberant way, than with more negative emotions, such as anger. For my shouting may be upsetting to others and that may be a reason not to shout. But unless I thought that I should have suppressed or attenuated my behaviour but failed to do so, the mere fact that I didn't do so is not an indication of any diminution or loss of control.

So because I do not see that these actions really involve any loss or diminution of control, I am not convinced that the point about control does the work that Raz wants it to do in undermining the view that these are fully intentional actions.

The second remark of Raz's relates to a claim he makes earlier in that paper, where he says that "although control is necessary to intentional action it is not sufficient" (1999, p. 40); and he adds that what is also required is 
that the agent "has a story to tell about it, a story that makes its performance intelligible" (1999, p. 40). This seems unobjectionable in itself. But when Raz provides this story for the examples like the one about shouting in anger, he says that "their explanations invoke considerations which are in fact reasons for actions, and which could have been their reasons" (1999, p. 43). He goes on:

For example, they may say they acted out of rage, adding or more commonly implying that the action was an appropriate expression of rage. Typically such explanations invoke motives rather than reasons, but they state facts (that I was enraged and the action was an appropriate expression of my rage) which are also reasons for the actions thus explained. (1999, p. 43)

I take it that what Raz means here is that these facts (that A was enraged and the action was an appropriate expression of her rage) could have been the agent's reason for, say, shouting, or breaking crockery, although they weren't her reasons. And part of the point of this remark is to emphasise how close these are to actions that he calls their "non-identical twins":

Purely expressive actions are non-identical twins of actions for a purely expressive reason, that is, actions one undertakes when the emotion swells within, and one says to oneself, "Why should I not let rip? It'll do me good", or "I am entitled to it", or something like that. (1999, p. 41)

These are, Raz says, "actions undertaken in order to express something" and, because they are "a tiny bit more calculated [than their non-identical twins], they are ordinary actions for a reason, albeit a purely expressive one" (1999, p. 41).

I'll make two points in response here. One is that I believe Raz's remarks about actions done "for a purely expressive reason" conflate facts that one can cite to explain why one did something: "I was enraged; the action was an appropriate expression, etc.", with facts that might have been one's reason for acting. It seems to me that, even in these cases, the kinds of facts Raz mentions are not the agent's reason for doing those things (shouting, etc.). For it is not as if, in these cases, one's reason is that since one is enraged, it would be appropriate to shout or to break crockery; that is, it is not the consideration that one is enraged that one would take to justify shouting, or to make it appropriate - typically, what one might think justified shouting would be whatever is the cause of one's fury. Rather, the function of the facts Raz mentions - that I am enraged etc., is (i) to place one's action in a pattern that gives its motive, i.e. shows it to be an instance of say, something done in rage; and (ii) an attempt to justify it by showing that rage, and rage expressed in just that way, was appropriate here. So to cite those facts is to explain my action: to make it intelligible that I should have done what I did, but not by giving my reasons for doing it. 
My second point is that, even if in the case of actions done for purely expressive reasons the kind of considerations Raz mentions are the agent's reasons for acting, nonetheless purely expressive actions (the examples that concern us) are still themselves not things done for a reason. For even if those facts could have been the agent's reasons in our kind of example, they were not, as a matter of fact, such reasons. And therefore they were not the reasons for which those actions were undertaken.

So I think Raz gives no persuasive argument to abandon the view that purely expressive actions are, at least sometimes, fully intentional but not done for a reason. And I see no reason not to accept this view. It may be true that these actions are not paradigmatic intentional actions - if paradigmatic intentional actions are actions done for reasons. But they are intentional actions nonetheless, and they are not uncommon in the repertoire of human behaviour.

\section{Conclusion}

There may be other examples of things done intentionally but not for a reason. Perhaps some things done out of habit, and things done to satisfy certain bodily desires may provide further examples. I do not have the space to explore those examples here. My purpose in this paper was to show that although many intentional actions are done for reasons, and perhaps this is true of paradigmatic intentional actions, there is a range of things that we seem to do intentionally but not for a reason. In themselves, many of these actions, in particular things done for no reason, tend to have little significance. And that may be a reason why they are often ignored in the philosophy of action. But however insignificant, they are important in order to understand both what reasons are, and also the kinds of agents we are. It seems that to insist that those things are done for reasons is to try to make us into much more rational creatures than we really are. $^{7}$

\section{Notes}

1. Though not, or not obviously, doing it with a further intention.

2. In characterising what acting for a reason is in this way, I am leaving aside complications introduced by the fact that one can act in the light of what only seems (to the agent) to be a fact, i.e., something that appeared to the agent to be the case but that wasn't the case. I leave them aside because I think those are, strictly speaking, cases of acting in the light of an apparent fact and hence of acting merely for an apparent reason. However, arguing for that claim would take us too far from our present concerns, and would introduce complications that are not to the point in this discussion. I discuss these cases in detail in Alvarez, 2008.

3. Again, I have argued for the claim that reasons are facts and not mental states of agents in detail in Alvarez, 2008.

4. This is a paraphrase of an argument given by Mele in support of the claim that desires are reasons for which one acts when one does something simply because one wants to. He writes: 
singings motivated by such desires are intentional actions; it is standardly held that intentional actions are done for reasons; this wholly intrinsic desire is the best available candidate for a relevant reason; the desire plays a central role in explaining the action; and the role is very similar to that played by typical Davidsonian reasons. (Mele, 2003, p. 82)

5. And here, I could not substitute "moving my arms and legs in this way" for "doing a cartwheel" because that would give my reason for moving my arms and legs in that way but not for doing the cartwheel. For, in my view similarly unsuccessful, attempts to argue that Davidson's model can fit all cases of voluntary action, see M. Smith, "Instrumental desires, instrumental rationality", $P A S 78,2004$, pp. 93-109. See also E. Harcourt's reply, Ibid, pp. 111-129.

6. It is interesting to note that this can be true of at least some animals. It is disputed whether animals act for reasons but it is less controversial that they act for purposes: they direct their behaviour towards certain ends. Now, at least some animals can also occasionally do things for no purpose. Sometimes such behaviour may come across as playful, sometimes just as plain odd. But if, say, a dog's behaviour were mostly so, that is, if the dog did many things for which no purpose could be discerned, then we'd judge that the dog had gone crazy.

7. This paper was presented at the "Human and Non-human Animal Agency" Conference held in Oslo in April 2008. The Conference was organized by the Centre for the Study of Mind in Nature (CSMN), University of Oslo, and was one of the Leverhulme-funded "Rethinking the Philosophy of Action Network" activities. I should like to thank the CSMN Centre and the Leverhulme Trust for making this event possible, and all participants for their comments.

\section{References}

Alvarez, M. (2008) "Reasons and the ambiguity of 'belief", Philosophical Explorations, 11(1), pp. 53-65.

Alvarez, M. (2009) "Actions, thought-experiments and the "principle of alternate possibilities", Australasian Journal of Philosophy, 87(1), pp. 61-81.

Anscombe, G.E.M. (1957) Intention (Oxford: Blackwell).

Aquinas, T. (1960-73) Summa Theologiae, T. Gilby (Ed.) (Cambridge: Blackfriars).

Davidson, D. (1980) Essays on Actions and Events (Oxford: Oxford University Press).

Frankfurt, H. (1969) "Alternate possibilities and moral responsibility", Journal of Philosophy, 66 , pp. $829-39$.

Harcourt, E. (2004) "Instrumental desires, instrumental rationality", Proceedings of the Aristotelian Society, Supplementary Volume 78, pp. 111-29.

Hurtshouse, R. (1991) “Arational action”, Journal of Philosophy, 83, pp. 291-95.

Mele, A.R. (2003) Motivation and Agency (Oxford: Oxford University Press).

O'Shaughnessy, B. (1980) The Will, 2 Vols. (Cambridge: Cambridge University Press).

Raz, J. (1999) Engaging Reason (Oxford: Oxford University Press).

Smith, M. (2004) "Instrumental desires, instrumental rationality", Proceedings of the Aristotelian Society, Supplementary Volume 78, pp. 93-109. 